\title{
The Prevalence of Visual Impairment and Refractive Errors among a Youth Population in Mozambique: Evidence of the Need for Intervention
}

\author{
Dulnério B. Sengo ${ }^{1}{ }^{(D}$, Isaura I. D. B. Dos Santos ${ }^{1}\left(\mathbb{D}\right.$, Momade F. Faquihe $^{1}$, Hermenegildo B. J. F. Tomo ${ }^{1}$, \\ Alcino M. Muaprato ${ }^{1}$, Sualé Puchar ${ }^{1}$, Guida M. R. J. Lôbo ${ }^{1}$, Inmaculada López-Izquierdo ${ }^{2, * \mathbb{D}}$ \\ and Pablo Caballero ${ }^{3}$ (D)
}

1 Faculty of Health Sciences, Lúrio University, Nampula City 3100, Mozambique; dulnerio@yahoo.com.br (D.B.S.); ibrito@unilurio.ac.mz (I.I.D.B.D.S.); mfaquihi@unilurio.ac.mz (M.F.F.); Htomo@unilurio.ac.mz (H.B.J.F.T.); alcinomuaprato87@gmail.com (A.M.M.); spuchar@unilurio.ac.mz (S.P.); guidademiranda@gmail.com (G.M.R.J.L.)

2 Department of Physics of Condensed Matter, Optics Area, University of Seville, Reina Mercedes St., 41012 Seville, Spain

3 Department of Community Nursing, Preventive Medicine and Public Health and History of Science, University of Alicante, 03690 Alicante, Spain; pablo.caballero@ua.es

* Correspondence: ilopez9@us.es; Tel.: +34-626310741

Citation: Sengo, D.B.; Dos Santos, I.I.D.B.; Faquihe, M.F.; Tomo, H.B.J.F.; Muaprato, A.M.; Puchar, S.; Lôbo, G.M.R.J.; López-Izquierdo, I.; Caballero, P. The Prevalence of Visual Impairment and Refractive Errors among a Youth Population in Mozambique: Evidence of the Need for Intervention. Children 2021, 8, 892. https://doi.org/10.3390/

children 8100892

Academic Editor: Michelle de Haan

Received: 30 August 2021

Accepted: 3 October 2021

Published: 6 October 2021

Publisher's Note: MDPI stays neutral with regard to jurisdictional claims in published maps and institutional affiliations.

Copyright: (c) 2021 by the authors. Licensee MDPI, Basel, Switzerland. This article is an open access article distributed under the terms and conditions of the Creative Commons Attribution (CC BY) license (https:// creativecommons.org/licenses/by/ $4.0 /)$.
Abstract: Visual impairment (VI) can significantly interfere in the child's daily activities and quality of life, having a negative effect on their development and learning. The aim of the study was to determine the prevalence of VI and associated demographic factors in students examined during the program "Moçambique te vejo melhor". This study was cross-sectional and retrospective, based on the 2018/19 edition of the program. Eye examinations were performed in secondary school students, aged between 12 and 20 years, of five districts in Nampula province. The examination included visual acuity, non-cycloplegic refraction and assessment of the anterior and posterior segment and ocular adnexa. The prevalence of uncorrected, presenting and best-corrected VI found was 18.3\%, $10.8 \%$, and $5.0 \%$, respectively. Refractive error (RE) had a prevalence of $24.7 \%$, and the age groups between 15-17 years and 18-20 years were significantly associated with myopia (with OR: 4.9 and OR: 8.8 , respectively), as well as the 11th and 12th grade (OR: 8.1 and OR: 10.7, respectively), and Malema district had association with myopia (ORa: 0.4) and hyperopia (ORa: 0.4 and OR: 0.3) as a protective factor. The prevalence of RE and VI was relatively high, showing the need for greater intervention at the school level.

Keywords: visual impairment; refractive error; schoolchildren; Mozambique

\section{Introduction}

The visual impairment (VI) results when an eye condition affects the visual system and one or more of its vision functions, such a visual acuity, can interfere significantly with daily activities and the individual's quality of life. VI can have a negative effect on development and learning for children, especially when it occurs during the first years of life. More than $85 \%$ of a child's learning is through visual stimuli [1,2].

Globally, it is estimated that 19 million children are blind or visually impaired, most of which is treatable or preventable, with a higher prevalence in low-income countries (9/10,000 children) compared to middle and high-income countries (7/10,000 and 4/10,000, respectively) [3].

Refractive errors (REs), eye disorders that occurs when the eye cannot clearly focus the images from the outside world, resulting from a mismatch between the axial length of the eye and its optical power [4,5], have been the main cause of VI in children, and they are the most prevalent visual disorder among children, affecting more than $20 \%$ [6]. REs 
have been associated with genetic and environmental factors, such as the influence of the gene loci (AREG, GABRR1, and PDE10A), near work distances and time spent in outdoor activities [7,8].

However, in Mozambique, there are no published studies on the prevalence and causes of VI in children. Data are needed to better plan strategies and policies in order to combat preventable VI in this group, thus reducing the high costs for the health system and society $[1,7]$.

In developing countries, where barriers to accessing eye health services prevail, screening programs in schools have the potential to promote eye health and the early detection of eye diseases and prevention of VI, particularly for children living in remote locations [3].

The program "Moçambique te vejo melhor" ("Mozambique see you better"), is developed by Universidade Lúrio, with the aim of promoting eye health in schools located in remote regions in Nampula and surrounding districts. Vision Screening has been one of the adopted mechanisms in the program, aiming to assess the eye health status and detect eye problems in students. This program has taken place during the month of September of each year and covers secondary level schools [9]. Therefore, this study aims to determine the prevalence of cases of VI and associated demographic factors in examined students during the program. The results obtained will provide important information for the improvement of the program and extension to other territories in the country.

\section{Materials and Methods}

This was a cross-sectional and retrospective study, based on clinical records of screenings carried out during the program "Moçambique te vejo melhor" 2018 and 2019 edition. Public schools from five districts (Mogovolas, Malema, Rapale, Meconta, and Mossuril) in Nampula province were part of the program. Nampula is located in the northeast of Mozambique, $2036 \mathrm{~km}$ (by road) from Maputo (capital of the country), with an area of $81,606 \mathrm{~km}^{2}$. It is limited to the north by the provinces of Cabo Delgado and Niassa, to the south by the province of Zambézia, and to the east by the Indian Ocean (Appendix A Figure A1) [10].

Nampula is the most populous province in Mozambique, with 20.6\% (5,758,920 inhabitants) of the general population, with the district of Mogovolas having 415,407 inhabitants, Malema with 223,791, Rapale with 174,707, Meconta with 250,425 and Mossuril with 142,787 inhabitants. The province has 3,002,676 children (0-17 years), where $934,543(31.1 \%)$ live in urban areas and 2,068,133 (68.9\%) in rural areas [11]. The "Moçambique te vejo melhor" program has been carried out in coordination with the district education directorates since 2014, with the aim promote the eye health of secondary school students (8th, 9th, 10th, 11th, and 12th grade) [9]. Currently, schooling in Mozambique is free and compulsory from the 1st to the 9 th grade (from 6 to 15 years).

Ethical aspects: The study was previously approved by the Institutional Committee of Bioethics for Health of Lúrio University (CIBSUL), on 17 December 2019, with ref: 51/Dec/CBISUL/19. During the program, students were examined through Signed Informed Consent (by parents and students aged $\geq 18$ years) and Assent (by students aged $<18$ years) written in Portuguese.

Clinical procedures: Clinical examinations were performed by a group of eight optometrists with more than five years of clinical experience each one. All cases of ocular pathologies and VI that did not improve with better correction were referred to the university clinic for complementary exams and identification of the cause. During the screening, socio-demographic data (district, academic level, age, gender) of the students were collected. To assess visual acuity (VA) logarithm tables of the minimum angle of resolution ( $\log M A R)$ were used, at $4 \mathrm{~m}$, monocularly, and the value recorded on the logMAR scale. The objective refraction was static (with a Keeller Professional Streak Retinoscope) without cycloplegic, and then the subjective refraction was performed. Due to the impossibility of using a cycloplegic, the use of an autorefractor was discarded as it could overestimate the prevalence of myopia in students with very active accommodation [12]. To evaluate the 
ocular structures, anterior and posterior segments, a point flashlight, magnifying loupe and a professional Keeler ophthalmoscope (for direct ophthalmoscopy) were used.

Inclusion and exclusion criteria: Clinical record that were duly completed and with the informed consent and assent forms signed were included in the study.

Variable definitions: The refractive state definition was based on the spherical equivalent $(\mathrm{SE}=$ sphere + half of the cylinder value) of the subjective refraction [6,7], and myopia was considered for $\mathrm{SE} \leq-0.50 \mathrm{D}$, hyperopia for $\mathrm{SE} \geq+2.00 \mathrm{D}$, and emmetropia for $\mathrm{SE}>-0.50 \mathrm{D}$ and $<+2.00 \mathrm{D}$. Regarding to severity, it was considered mild for REs $\leq 3.00 \mathrm{D}$, moderate between 3.25 and $6.00 \mathrm{D}$, and high for $>6.00 \mathrm{D}$ [7]. Astigmatism was considered (using negative cylinders) for values $\leq-0.75 \mathrm{D}$. The type of astigmatism was defined according to the cylinder axis, as with-the-rule (WTR) for axes from $1^{\circ}$ to $15^{\circ}$ and from $165^{\circ}$ to $180^{\circ}$, against-the-rule (ATR) for axes from $75^{\circ}$ to $105^{\circ}$, and oblique (OBL) for axes from $16^{\circ}$ to $74^{\circ}$ and $106^{\circ}$ to $164^{\circ}$ [6]. Visual impairment (VI) and its respective category were defined based on the patient's VA (logMAR scale). VI was considered for VA $\geq 0.30$ ( $\leq 6 / 12$ Snellen) [13], being mild for VA between 0.30 and $0.50(6 / 12$ and $6 / 18$ Snellen), moderate $>0.5$ to $1.0(<6 / 18$ to $6 / 60$ Snellen), severe $>1.0$ to 1.30 ( $<6 / 60$ to $3 / 60$ Snellen), and blindness $>1.30(<3 / 60$ Snellen) [14]. "Uncorrected VI" was defined on the basis of uncorrected VA. While the "presenting VI" was according to the VA taken in the condition in which the patient presented himself for the exam, using his correction if any. "Bestcorrected VI" was defined based on the VA taken after subjective refraction [15]. Cases of bilateral VI, the VA of the best eye was considered.

Statistical Analyses: A socio-demographic description of the sample was made, and the frequency of VI and its causes was determined. The correlation between the RE of the right and left eye was analyzed using Spearman's correlation coefficient, and a statistical significance and high correlation was found (Rs: $0.85 ; p<0.001$ ), which is the reason that statistical analysis was made only with data from the right eye of each patient, as was done in similar studies [16]. For study the association between refractive error and socio-demographic characteristics (age, gender, school level, and district) the Odds Ratio and adjusted Odds Ratio (OR and ORa) was calculated by logistic and multiple regression with successive steps forward, with $95 \%$ confidence interval (CI) and 5\% significance level. The adjustment was carried out using all available sociodemographic variables. All data analysis was performed using SPSS version 23.0 (SPSS Inc., Chicago, IL, USA). Statistical power [17] was calculated with the package WebPower of the language and environment for statistical computing R [18].

\section{Results}

In a total of 592 participants, 575 had the clinical records duly completed and with the respective signed informed consent form, as they took part in the study. The participants were aged between 12 and 20 years, with an average of $15.13( \pm 2.24)$ years. The majority $(56.9 \%)$ of the participants were female. There were more students in the 8 th grade $(31.1 \%)$ followed by those in grade $9(21.6 \%)$ in this study's sample. Most participants were from Meconta (39.5\%) and Mogovolas (25.7\%) districts (Table 1).

The prevalence of uncorrected VI was $18.3 \%$, The 18-20 age group had the highest prevalence $(29.2 \%)$. Regarding to the school level, the prevalence was higher in the 11th and 12th grade (with 26.4\% and 31.1\%, respectively). The district of Meconta and Mossuril had the highest prevalence (both with 21.1\%) (Table 1).

The prevalence of presenting VI was $10.8 \%$, and the 18-20 age group had the highest prevalence $(13.3 \%)$. As for the school level, the 11th grade had the highest prevalence $(15.1 \%)$, and Malema had the highest prevalence among the districts involved (12.3\%) (Table 1). 
Table 1. Socio-demographic characteristics of participants and prevalence of visual impairment.

\begin{tabular}{|c|c|c|c|c|c|c|c|c|}
\hline \multirow[b]{2}{*}{ Variables } & \multirow[b]{2}{*}{$\mathbf{N}$} & \multirow[b]{2}{*}{$\%$} & \multicolumn{2}{|c|}{$\begin{array}{l}\text { Uncorrected Visual } \\
\text { Impairment }\end{array}$} & \multicolumn{2}{|c|}{$\begin{array}{c}\text { Presenting Visual } \\
\text { Impairment }\end{array}$} & \multicolumn{2}{|c|}{$\begin{array}{c}\text { Best-Corrected Visual } \\
\text { Impairment } \\
\end{array}$} \\
\hline & & & $\mathbf{N}$ & $\%$ & $\mathbf{N}$ & $\%$ & $\mathbf{N}$ & $\%$ \\
\hline \multicolumn{9}{|l|}{ Age (years) } \\
\hline $12-14$ & 259 & 45.0 & 28 & 10.8 & 22 & 8.5 & 15 & 5.8 \\
\hline $15-17$ & 203 & 35.3 & 44 & 21.7 & 25 & 12.3 & 9 & 4.4 \\
\hline $18-20$ & 113 & 19.7 & 33 & 29.2 & 15 & 13.3 & 5 & 4.4 \\
\hline \multicolumn{9}{|l|}{ Gender } \\
\hline Male & 248 & 43.1 & 48 & 19.4 & 29 & 11.7 & 13 & 5.2 \\
\hline Female & 327 & 56.9 & 57 & 17.4 & 33 & 10.1 & 16 & 4.9 \\
\hline \multicolumn{9}{|l|}{ Grade } \\
\hline 8th & 179 & 31.1 & 15 & 8.4 & 12 & 6.7 & 9 & 5.0 \\
\hline 9 th & 124 & 21.6 & 19 & 15.3 & 15 & 12.1 & 8 & 6.5 \\
\hline 10th & 60 & 10.4 & 10 & 16.7 & 5 & 8.3 & 3 & 5.0 \\
\hline 11th & 106 & 18.4 & 28 & 26.4 & 16 & 15.1 & 4 & 3.8 \\
\hline 12th & 106 & 18.4 & 33 & 31.1 & 14 & 13.2 & 5 & 4.7 \\
\hline \multicolumn{9}{|l|}{ District } \\
\hline Megovolas & 148 & 25.7 & 19 & 12.8 & 14 & 9.5 & 7 & 4.7 \\
\hline Malema & 73 & 12.7 & 13 & 17.8 & 9 & 12.3 & 4 & 5.5 \\
\hline Rapale & 64 & 11.1 & 13 & 20.3 & 7 & 10.9 & 4 & 6.3 \\
\hline Meconta & 227 & 39.5 & 48 & 21.1 & 26 & 11.5 & 10 & 4.4 \\
\hline Mossuril & 63 & 11 & 12 & 21.1 & 6 & 9.5 & 4 & 6.3 \\
\hline \multicolumn{9}{|l|}{ VI category } \\
\hline Normal & & & 470 & 81.7 & 513 & 89.2 & 546 & 95.0 \\
\hline Mild VI & & & 32 & 5.6 & 31 & 5.4 & 15 & 2.6 \\
\hline Moderate VI & & & 70 & 12.2 & 28 & 4.9 & 10 & 1.7 \\
\hline Severe VI & & & 2 & 0.3 & 1 & 0.2 & 2 & 0.3 \\
\hline Blindness & & & 1 & 0.2 & 2 & 0.3 & 2 & 0.3 \\
\hline \multicolumn{9}{|l|}{ VI laterality } \\
\hline Normal & & & 470 & 81.7 & 513 & 89.2 & 546 & 95.0 \\
\hline Unilateral & & & 16 & 2.8 & 16 & 2.6 & 19 & 3.3 \\
\hline Bilateral & & & 89 & 15.5 & 46 & 8.2 & 10 & 1.7 \\
\hline
\end{tabular}

CI: confidence interval, VI: vision impairment.

The prevalence of best-corrected VI was 5.0\%, and the age group with the highest prevalence was 12-14 years (5.8\%). Regarding to the school level, the 9th grade had the highest prevalence (6.5\%). Rapale and Mossuril had the highest prevalence among districts (6.3\%) (Table 1).

For the three types of VI, male gender had the highest prevalence and was mostly mild to moderate (Table 1).

Among patients with presenting VI, 53\% achieved normal vision with the best correction.

Overall, refractive errors (REs) had a prevalence of $24.7 \%$, mainly constituted by hyperopia (14.3\%) to the detriment of myopia (10.4\%). The age groups between $15-17$ years and 18-20 years were significantly associated with the occurrence of myopia (with OR: 4.9 and ORa: 5.1, and OR: 8.8 and ORa: 12.5, respectively), with higher risk in the latter (Table 2).

The grade 11 and 12 had a significant association with the occurrence of myopia (OR: 8.1 and OR: 10.7, respectively). While Malema district had a significant association with myopia (ORa: 0.4 ) and hyperopia (ORa: 0.4 and OR: 0.3 ), however, as a protective factor for its occurrence (Table 2). 
Table 2. Prevalence of refractive error and association with socio-demographic characteristics.

\begin{tabular}{|c|c|c|c|c|c|c|c|c|c|}
\hline \multirow[b]{3}{*}{ Variables } & \multirow{3}{*}{$\begin{array}{c}\text { Emmetropia } \\
\%(\mathrm{~N})\end{array}$} & \multicolumn{8}{|c|}{ Refractive Error } \\
\hline & & & Myo & & & & Hyperopia & & \\
\hline & & $\%(\mathrm{~N})$ & OR (CI95\%) & ORa (CI95\%) & Power & $\%(\mathrm{~N})$ & OR (CI95\%) & ORa (CI95\%) & Power \\
\hline \multicolumn{10}{|l|}{ Age (years) } \\
\hline $12-14$ & $81.9(212)$ & $3.1(8)$ & 1 & 1 & & $15.1(39)$ & 1 & 1 & \\
\hline $15-17$ & $71.9(146)$ & $13.3(27)$ & $4.9^{* *}(2.2-11.1)$ & $5.1^{* *}(2.3-11.6)$ & 0.999 & $14.8(30)$ & $1.1(0.7-1.9)$ & n.s. & 0.131 \\
\hline $18-20$ & $66.4(75)$ & $22.1(25)$ & $8.8^{* *}(3.8-20.4)$ & $12.5^{* *}(5.2-30.1)$ & 0.999 & $11.5(13)$ & $0.9(0.5-1.9)$ & n.s. & 0.068 \\
\hline \multicolumn{10}{|l|}{ Gender } \\
\hline Male & $74.6(185)$ & $10.9(27)$ & 1 & 1 & & $14.5(36)$ & 1 & 1 & 0.069 \\
\hline Female & $75.5(248)$ & $10.1(33)$ & $0.9(0.5-1.6)$ & n.s. & 0.105 & $14.1(46)$ & $1.0(0.6-1.5)$ & n.s. & \\
\hline \multicolumn{10}{|l|}{ Grade } \\
\hline 8 th & $84.4(151)$ & $2.8(5)$ & 1 & 1 & & $12.8(23)$ & 1 & 1 & \\
\hline 9th & $77.4(96)$ & $5.6(7)$ & $2.2(0.7-7.1)$ & n.s. & 0.677 & $16.9(21)$ & $1.4(0.8-2.7)$ & n.s. & 0.567 \\
\hline 10th & $78.3(47)$ & $8.3(5)$ & $3.2(0.9-11.6)$ & n.s. & 0.907 & $13.3(8)$ & $1.1(0.5-2.7)$ & n.s. & 0.088 \\
\hline 11th & $67.0(71)$ & $17.9(19)$ & $8.1^{* *}(2.9-22.5)$ & n.s. & 0.999 & $15.1(16)$ & $1.5(0.7-3.0)$ & n.s. & 0.566 \\
\hline 12th & $64.2(68)$ & $22.6(24)$ & $10.7^{* *}(3.9-29.1)$ & n.s. & 0.999 & $13.2(14)$ & $1.4(0.7-2.8)$ & n.s. & 0.144 \\
\hline \multicolumn{10}{|l|}{ District • } \\
\hline Megovolas & $77.0(114)$ & $6.8(10)$ & $0.6(0.3-1.1)$ & n.s. & 0.216 & $16.2(24)$ & $1.2(0.7-2.0)$ & n.s. & 0.224 \\
\hline Malema & $82.2(60)$ & $12.3(9)$ & $1.1(0.5-2.3)$ & $0.4 *(0.2-1.0)$ & 0.098 & $5.5(4)$ & $0.3 *(0.1-0.9)$ & $0.4^{*}(0.1-1.0)$ & 0.999 \\
\hline Rapale & $75.0(48)$ & $10.9(7)$ & $1.1(0.5-2.5)$ & n.s. & 0.138 & $14.1(9)$ & $1.0(0.5-2.1)$ & n.s. & 0.171 \\
\hline Meconta & $74.4(169)$ & $12.8(29)$ & $1.5(1.0-1.1)$ & n.s. & 0.254 & $12.8(29)$ & $0.9(0.5-1.4)$ & n.s. & 0.793 \\
\hline Mossuril & $66.7(42)$ & $7.9(5)$ & $0.8(0.3-2.2)$ & n.s. & 0.229 & $25.4(16)$ & $2.3 *(1.2-4.2)$ & $2.0 *(1.1-3.8)$ & 0.999 \\
\hline Total & $75.3(433)$ & $10.4(60)$ & & & & $14.3(82)$ & & & \\
\hline
\end{tabular}

- The reference group is the rest of the districts; CI: confidence interval, OR: Odds ratio, ORa: adjusted Odds Ratio by socio-demographic variables. Power, Statistic Power for logistic regression. * Statistic signification $<0.05,{ }^{* *}$ Statistic signification $<0.001$.

REs were mostly mild and moderate. Astigmatism had a prevalence of $8.3 \%$, and it was mostly WTR with $6.4 \%$ (Table 3 ).

Table 3. Characteristics of refractive errors.

\begin{tabular}{|c|c|c|c|c|c|c|c|c|c|c|}
\hline Refractive State & Emmetropia & \multicolumn{3}{|c|}{ Myopia } & \multicolumn{3}{|c|}{ Hyperopia } & \multicolumn{3}{|c|}{ Astigmatism } \\
\hline$n(\%)$ & $433(75.3)$ & & $60(10.4)$ & & & $82(14.3)$ & & & $48(8.3)$ & \\
\hline $\begin{array}{c}\text { Severity } \\
n(\%)\end{array}$ & & $\begin{array}{c}\text { mild } \\
37(6.4)\end{array}$ & $\begin{array}{l}\text { moderate } \\
22(3.8)\end{array}$ & $\begin{array}{l}\text { high } \\
1(0.2)\end{array}$ & $\begin{array}{c}\text { mild } \\
54(9.4)\end{array}$ & $\begin{array}{l}\text { moderate } \\
27(4.7)\end{array}$ & $\begin{array}{l}\text { high } \\
1(0.2)\end{array}$ & $\begin{array}{l}\text { WTR }^{1} \\
37(6.4)\end{array}$ & $\begin{array}{l}\text { ATR }^{2} \\
4(0.7)\end{array}$ & $\begin{array}{l}\mathrm{OBL}^{3} \\
7(1.2)\end{array}$ \\
\hline
\end{tabular}

In 142 patients with RE, only 33.1\% used correction. The prevalence of uncorrected refractive error (URE) was $16.5 \%$.

The main cause of uncorrected VI was RE and amblyopia, with almost $40 \%$ resolved with the usual correction (day-to-day), and a little more than 70\% resolved with the best correction. For the best-corrected VI, the main cause was amblyopia, followed by corneal opacity and congenital cataract, as the most prominent ones (Table 4).

Table 4. Causes of visual impairment.

\begin{tabular}{lcccccc}
\hline \multirow{2}{*}{ Causes } & \multicolumn{2}{c}{ Uncorrected VI } & \multicolumn{2}{c}{ Presenting VI } & \multicolumn{2}{c}{ Best-Corrected VI } \\
& $\mathbf{N}$ & $\mathbf{\%}$ & $\mathbf{N}$ & $\mathbf{\%}$ & $\mathbf{N}$ & $\mathbf{\%}$ \\
\hline Refractive error & 76 & 72.4 & 33 & 31.4 & 0 & 0.0 \\
Amblyopia & 16 & 15.2 & 16 & 15.2 & 16 & 15.2 \\
Congenital cataract & 4 & 3.8 & 4 & 3.8 & 4 & 3.8 \\
Corneal opacity & 5 & 4.8 & 5 & 4.8 & 5 & 4.8 \\
Toxoplasmosis & 1 & 1.0 & 1 & 1.0 & 1 & 1.0 \\
Retinal disorders & 1 & 1.0 & 1 & 1.0 & 1 & 1.0 \\
Other causes & 2 & 1.9 & 2 & 1.9 & 2 & 1.9 \\
Total & 105 & 100 & 62 & 59.0 & 29 & 27.6 \\
\hline VI: & & & & &
\end{tabular}

VI: vision impairment. 


\section{Discussion}

This study is the result of a visual health screening program promoted by Universidade Lúrio, which covers the remote areas of Nampula and surrounding districts. The research offers important preliminary results for the improvement of the program and extension to other regions of the country. The evidences on the magnitude and causes of VI are useful for monitoring progress and identifying priorities as part of the World Health Organization's 2014-2019 global eye health action plan [19].

The prevalence of Uncorrected VI found in the study was 18.3\%, similar to the study carried out in Vietnam [20] and Nepal-Kathmandu [21], which was $19.4 \%$ and $18.6 \%$, respectively. However, in Ghana [22], the prevalence of Uncorrected VI was much lower $(3.7 \%)$ than in other studies, which may be associated with the low proportion $(3.2 \%)$ of myopia found in this study.

For presenting VI, the prevalence was $10.8 \%$, similar to what was found in Nepal [21] and Malaysia [23], which was $9.1 \%$ and $10.1 \%$, respectively. However, in Brazil [24] and Vietnam [20], the prevalence was slightly higher (with $14.5 \%$ and $12.2 \%$, respectively), and in Ghana [22] it was much lower (3.7\%). The prevalence of presenting VI is an indicator that so much reflects the coverage of the health system and accessibility to eye health services, which may vary depending on each country and region, and may also be determined by economic and socio-cultural factors that lead people to live with VI. In general, the most remote and poorest regions of low-income countries are the most disadvantaged, have less access to eye health services [25]. The unavailability of eye health services and geographic and financial limitations for their access can be pointed out as possible causes for a higher prevalence of presenting VI [26,27], since the five districts involved do not have optometrists or ophthalmologists for eye health services. The districts of Mogovolas, Malema, Rapale, and Meconta each have an ophthalmology technician (with an average level of education and training lasting 18 months), and Mossuril does not have any professional [28].

Therefore, these districts have a ratio of eye health professionals per number of inhabitants below that recommended by the World Health Organization (1 Ophthalmic technician per 100,000 inhabitants, 1 optometrist for 250,000 inhabitants, and 1 ophthalmologist per 250,000 inhabitants) [29].

The main cause of VI was RE (87.6\%), coinciding with studies from Vietnam [20], Nepal [21], Malaysia [23], and Ghana [22].

However, REs are reaffirmed as the main cause of VI, although the effort made under the WHO Vision 2020 initiative [30], it is still a challenge for the health system of several countries, including Mozambique.

The prevalence of RE was $24.7 \%$ (with $14.3 \%$ hyperopia and $10.4 \%$ myopia), similar to the study carried out in Egypt [31] whose prevalence was 22.8\%, but myopia (71\%) was predominant in relation to hyperopia (29\%). While in Saudi Arabia [7], the prevalence was higher $(55.5 \%)$, and myopia (53.3\%) was more prevalent than hyperopia (2.2\%). In Ethiopia [32], the prevalence was lower (9.4\%), with myopia having a higher proportion (31.6\%) than hyperopia (26.4\%).

Therefore, myopia was dominant in other studies, which may be associated with the fact that some studies used an autorefractor without cycloplegic, which overestimates the prevalence of myopia [12], and in others, refraction was performed only in schoolchildren with VA less than $6 / 6$, which may underestimate the prevalence of hyperopia, as it does not always have a low VA.

In a study in Burkina Faso [33], using the same refraction technique as our study, a higher prevalence of hyperopia $(4.9 \%)$ was found in relation to myopia $(0.5 \%)$, which was associated with the characteristics of the population in that country (such as low literacy and a non-urban lifestyle). In another study carried out in Poland [34], with cycloplegic retinoscopy, a higher prevalence of hyperopia (38\%) than myopia (13\%) was found. In addition to the use of cycloplegic, it may be associated with the definition of hyperopia adopted in this study (as S.E of at least +1.00D). In another study carried out in 
Northern Ireland [35], myopia was lower (2.8\%) than hyperopia (26\%) in children aged 6-7 years, while in children aged $12-13$ years myopia was higher $(17.7 \%)$ than hyperopia (14.7\%). In these studies from Northern Ireland [35] and Poland [34], as well as in our study, the prevalence of myopia tended to increase with age, and the opposite happened with hyperopia, and a positive correlation was found between the prevalence of myopia and age $(p<0.001)$, as well as a negative correlation between hyperopia and age $(p<0.001)$ in Poland [34]. The age groups between 15-17 and 18-20 years old were associated, as a risk factor, to the occurrence of myopia, as well as the 11th and 12th grade, while Malema district was associated, as protective factor, for both myopia and hyperopia. In the study carried out in Egypt [31], residence (urban/rural) was not associated with RE, unlike hours in front of the television or computer, which had a significant association with RE. In Iran [6], myopia was significantly associated with male gender (OR: 2.73, $p<0.001)$ and residence, being higher in students living in urban areas $(p=0.019)$, while in Ireland [13], myopia and hyperopia did not have significant association with gender, residence (rural/urban) and socioeconomic level, but had a significant association with age and ethnicity $(p<0.001)$.

The occurrence of different REs may be associated with various exposure factors among different populations, and myopia is associated with high exposure to electronic device screens (such as smartphones, computers, and tablets) as well as great educational pressure and reduced hours spent outdoors, typical of urban areas and developed countries [36]. However, our study involved schoolchildren living in rural regions of northern Mozambique, which may be associated with a low prevalence of myopia to the detriment of hyperopia.

In Mozambique, education is compulsory and free from the grade 1 to 9, which may suggest that students who are able to continue their studies in the post-compulsory phase, until the 11th and 12th grade, have better socioeconomic conditions; however, greater purchasing power associated with access to technologies and greater educational pressure, resulting in a higher incidence of myopia in this group.

The prevalence of uncorrected refractive error (URE) was 16.5\%, higher than that found in studies in Nigeria [37], Ethiopia [38] and Indonesia [39], which was 4.8\%, 9.5\%, and $12.1 \%$, respectively. The prevalence of URE so much reflects the accessibility of eye health services in the country, and it is clear that it is still a major challenge for the National Health System. This is a public health problem that interferes so much in the quality of life and productivity of the individual, with negative effects on the cognitive and psychosocial development of children, however, it is greatly underestimated, since in many countries there is no really effective screening system for eye problems in children [40,41].

REs can be easily corrected with the use of glasses, contact lenses or refractive surgery [42], and its correction would bring significant improvements in health indicators, since, within students with presenting VI, 53\% had normal vision with their best correction. Thus, there is a need for future large-scale studies that identify the barriers to accessing eye health services (consultation, purchase of glasses, medication, surgery) in this portion of the population and subsequent intervention in the short, medium and long term in order to reverse this scenario and combating preventable VI.

It is necessary to implement public policies that support a truly effective, comprehensive and timely screening system, according to evidence-based clinical practice guidelines [43], and invest in eye health professionals training, in order to improve the ratio of professionals per population in each district and guarantee universal access to eye health services.

This study was limited by the impossibility of using cycloplegics in screenings during objective refraction, adopting static refraction with the use of a Keeller Professional Streak Retinoscope and subjective refraction to avoid overestimating the prevalence of myopia. Studies have shown that non-cycloplegic retinoscopy and subjective refraction are clinically accurate and can be applied to screening for refractive error in children, showing good agreement with cycloplegic refraction [44,45]. Furthermore, due to the difficulty of performing repeated measurements among children during the program, due to the 
limited time of the program, a reliability study using intra- and inter-observer measures was not performed.

As for the factors associated with the occurrence of REs, the present study was not thorough in this approach, and taking into account the relatively high prevalence of REs found $(24.7 \%)$, there is a need for studies that assess in more detail the risk factors that contribute to the occurrence of REs, as well as protective factors, such as the case of Malema district (in relation to hyperopia and myopia), it is important to investigate what makes this district different from others, since all involved districts were socio-economically similar.

In order to improve eye health indicators in children, it would be important that the program also include children from lower levels of education (pre-school and primary), since the second leading cause of VI in this portion was amblyopia, which is more efficiently treated when detected early, within the sensitive period of development (up to 7 years of age) [46]. The program should include an educational component for teachers and guardians (parents), so that they know the signs and symptoms, and the risk factors associated with the development of REs, since the way in which children are educated, implementing healthy habits such as reducing exposure to electronic device screens, as well as spending more time outdoors, can positively contribute to reducing the incidence of myopia [47]. It is important that parents are aware of the importance of periodic eye examination for early detection and preventing preventable and treatable blindness.

\section{Conclusions}

The prevalence of RE and VI found in this study is relatively high, and most causes of VI are preventable and treatable. The results provide preliminary evidence of the need for greater intervention at the school level as it is a privileged and strategic place to promote eye health. Efforts are needed, especially to bring visual health services to remote and inaccessible areas.

Author Contributions: Conception, D.B.S., I.I.D.B.D.S., M.F.F. and G.M.R.J.L.; methodology, D.B.S., H.B.J.F.T., P.C. and I.L.-I.; analysis and interpretation of data, D.B.S., M.F.F., S.P. and A.M.M.; original draft preparation, D.B.S., I.I.D.B.D.S., S.P. and A.M.M.; review and editing, D.B.S., G.M.R.J.L., P.C. and I.L.-I.; Supervision, P.C. and I.L.-I. All authors read and approved the final version of the manuscript.

Funding: The "Moçambique te vejo melhor" program is fully funded by Lurio University. This research received no external funding.

Institutional Review Board Statement: The study was approved by the Institutional Bioethics Committee for Health of the University of Lúrio (CIBSUL), on 17 December 2019, with ref: 51/Dec/CBISUL/19.

Informed Consent Statement: Informed consent was obtained from all parents and students involved in the study.

Acknowledgments: The main author (DS) would like to thank the other authors for their important contribution to this study that is part of his doctoral thesis.

Conflicts of Interest: The authors declare no conflict of interest. 


\section{Appendix A}

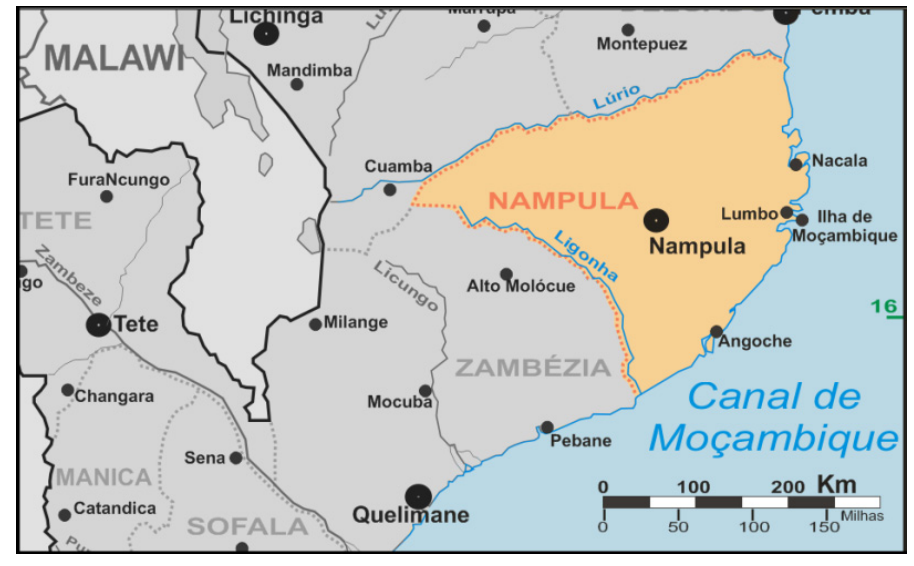

(a)

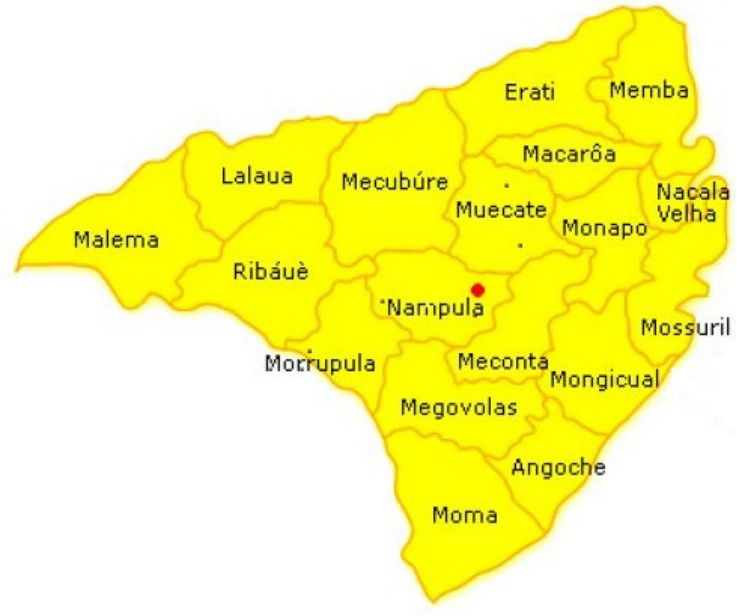

(b)

Figure A1. (a) Location of Nampula within Mozambique (b) Distribution of the districts of Nampula.

\section{References}

1. Atowa, U.C.; Hansraj, R.; Wajuihian, S.O. Visual problems: A review of prevalence studies on visual impairment in school-age children. Int. J. Ophthalmol. 2019, 12, 1037-1043. [CrossRef]

2. Shi, X.-Y.; Ke, Y.-F.; Jin, N.; Zhang, H.-M.; Wei, R.-H.; Li, X.-R. The prevalence of vision impairment and refractive error in 3654 first year students at Tianjin Medical University. Int. J. Ophthalmol. 2018, 11, 1698-1703. [CrossRef]

3. Burnett, A.M.; Yashadhana, A.; Lee, L.; Serova, N.; Brain, D.; Naidoo, K. Interventions to improve school-based eye-care services in low- and middle-income countries: A systematic review. Bull. World Health Organ. 2018, 96, 682D-694D. [CrossRef] [PubMed]

4. World Health Organization (WHO). Blindness and Vision Impairment: Refractive Errors. 2013. Available online: https: //www.who.int/news-room/q-a-detail/blindness-and-vision-impairment-refractive-errors (accessed on 27 September 2021).

5. Harb, E.N.; Wildsoet, C.F. Origins of Refractive Errors: Environmental and Genetic Factors. Annu. Rev. Vis. Sci. $2019,5,47-72$.

6. Hashemi, H.; Rezvan, F.; Beiranvand, A.; Papi, O.-A.; Yazdi, H.H.; Ostadimoghaddam, H.; Yekta, A.A.; Norouzirad, R.; Khabazkhoob, M. Prevalence of Refractive Errors among High School Students in Western Iran. J. Ophthalmic Vis. Res. 2014, 9 , 232-239.

7. Alsaqr, A.; Abu Sharha, A.; Fagehi, R.; Almutairi, A.; Alosaimi, S.; Almalki, A.; Alluwaymi, A. The visual status of adolescents in Riyadh, Saudi Arabia: A population study. Clin. Ophthalmol. 2018, 12, 965-972. [CrossRef] [PubMed]

8. Qian, X.; Liu, B.; Wang, J.; Wei, N.; Qi, X.; Li, X.; Li, J.; Zhang, Y.; Hua, N.; Ning, Y.; et al. Prevalence of refractive errors in Tibetan adolescents. BMC Ophthalmol. 2018, 18, 118. [CrossRef] [PubMed]

9. Universidade Lúrio, Departamento de Pesquisa e Extensão. Programa Mocambique te Vejo Melhor; Universidade Lúrio, Departamento de Pesquisa e Extensão: Nampula, Moçambique, 2013.

10. Ministério da Indústria e Comércio Mozambique. Localização e Caracterização da Província de Nampula. 2018. Available online: https:/ / www.mic.gov.mz/por/Dir-Provinciais/DPIC-Nampula (accessed on 27 September 2021).

11. Instituto Nacional de Estatística. Resultados Definitivos do Censo 2017-Recenseamento Geral da População e Habilitação; 2019; pp. 1-214. Available online: http://www.ine.gov.mz/iv-rgph-2017/mocambique/censo-2017-brochura-dos-resultadosdefinitivos-do-iv-rgph-nacional.pdf (accessed on 27 September 2021).

12. Mahayana, I.T.; Indrawati, S.G.; Pawiroranu, S. The prevalence of uncorrected refractive error in urban, suburban, exurban and rural primary school children in Indonesian population. Int. J. Ophthalmol. 2017, 10, 1771-1776. [CrossRef]

13. Harrington, S.C.; Stack, J.; Saunders, K.; O’Dwyer, V. Refractive error and visual impairment in Ireland schoolchildren. Br. J. Ophthalmol. 2019, 103, 1112-1118. [CrossRef]

14. World Health Organization. Cumulative Official Updates to ICD-10; World Health Organization: Delhi, India, 2008.

15. Resnikoff, S.; Pascolini, D.; Mariotti, S.P.; Pokharel, G.P. Global magnitude of visual impairment caused by uncorrected refractive errors in 2004. Bull. World Health Organ. 2008, 86, 63-70. [CrossRef]

16. Bourne, R.R.A.; Dineen, B.P.; Ali, S.M.; Noorul Huq, D.M.; Johnson, G.J. Prevalence of refractive error in Bangladeshi adults: Results of the National Blindness and Low Vision Survey of Bangladesh. Ophthalmology 2004, 111, 1150-1160. [CrossRef] [PubMed]

17. Zhang, Z.; Mai, Y. WebPower: Basic and Advanced Statistical Power Analysis. 2021. Available online: https://cran.r-project.org/ package $=$ WebPower (accessed on 30 September 2021).

18. Zhang, Z.; Yuan, K.-H. Practical Statistical Power Analysis Using Webpower and R; ISDSA Press: Granger, IN, USA, 2018. Available online: https:/ / webpower.psychstat.org/wiki/models/index (accessed on 15 May 2021). 
19. World Health Organization. Universal Eye Health: A Global Action Plan 2014-2019; World Health Organization: Geneva, Switzerland, 2013.

20. Paudel, P.; Ramson, P.; Naduvilath, T.; Wilson, D.; Phuong, H.T.; Ho, S.M.; Giap, N.V. Prevalence of vision impairment and refractive error in school children in Ba Ria-Vung Tau province, Vietnam. Clin. Exp. Ophthalmol. 2013, 42, 217-226. [CrossRef]

21. Sapkota, Y.D.; Adhikari, B.N.; Pokharel, G.P.; Poudyal, B.K.; Ellwein, L.B. The Prevalence of Visual Impairment in School Children of Upper-Middle Socioeconomic Status in Kathmandu. Ophthalmic Epidemiol. 2008, 15, 17-23. [CrossRef] [PubMed]

22. Kumah, B.D.; Ebri, A.; Abdul-Kabir, M.; Ahmed, A.-S.; Koomson, N.Y.; Aikins, S.; Aikins, A.; Amedo, A.; Lartey, S.; Naidoo, K. Refractive Error and Visual Impairment in Private School Children in Ghana. Optom. Vis. Sci. 2013, 90, 1456-1461. [CrossRef]

23. Goh, P.-P.; Abqariyah, Y.; Pokharel, G.P.; Ellwein, L.B. Refractive Error and Visual Impairment in School-Age Children in Gombak District, Malaysia. Ophthalmology 2005, 112, 678-685. [CrossRef]

24. Vieira, J.K.; Rezende, G.X.; Anastácio, L.D.B.; Filho, R.T.D.F.; Benevides, H.C.C.; Fonseca, J.M.; Pereira, M.V.S.; Mota, F.M Prevalence of visual disorders in school children. Rev. Bras. Oftalmol. 2018, 77, 175-179. [CrossRef]

25. du Toit, R.; Faal, H.B.; Etya'ale, D.; Wiafe, B.; Mason, I.; Graham, R.; Bush, S.; Mathenge, W.; Courtright, P. Evidence for integrating eye health into primary health care in Africa: A health systems strengthening approach. BMC Health Serv. Res. 2013, 13, 102. [CrossRef] [PubMed]

26. Akowuah, P.K. An Assessment of the Human Resource in Eye Care in the Upper East Region, Ghana. Adv. Ophthalmol. Vis. Syst. 2017, 7, 00245. [CrossRef]

27. Onakpoya, O.H.; Adeoye, A.O.; Adegbehingbe, B.O.; Akinsola, F.B. Assessment of human and material resources available for primary eye-care delivery in rural communities of southwestern Nigeria. West Indian Med. J. 2009, 58, 472-475.

28. Direcção Provincial de Saúde de Nampula. Relatório de Desenvolvimento de Recurso Humano para Saúde; Cidade de Nampula: Nampula, Mozambique, 2018.

29. World Health Organization-Africa Regional. Core Competencies for the Eye Health Workforce in the WHO African Region; World Health Organization-Africa Regional: Kano, Nigeria, 2019.

30. Pizzarello, L.; Abiose, A.; Ffytche, T.; Duerksen, R.; Thulasiraj, R.; Taylor, H.; Fall, H.; Rao, G. VISION 2020: The Right to Sight: A global initiative to eliminate avoidable blindness. Arch. Ophthalmol. 2004, 122, 615-620. [CrossRef]

31. Arafa, A.E.E.-D.; Ewis, A.A.E.; Mahran, W.M.; Mohamed, A.A.E.; El-Shabrawy, E.M. Prevalence and risk factors of refractive errors among preparatory school students in Beni-Suef, Egypt. J. Public Health 2019, 27, 43-47. [CrossRef]

32. Belaynew, W.T.; Destaye, S.; Yared, A.W.; Zelalem, E.; Ayanaw, T. Prevalence of refractive errors among school children in Gondar town, northwest Ethiopia. Middle East Afr. J. Ophthalmol. 2012, 19, 372-376. [CrossRef]

33. Anera, R.G.; Jiménez, J.R.; Soler, M.; Pérez, M.A.; Jiménez, R.; Cardona, J.C. Prevalence of Refractive Errors in School-Age Children in Burkina Faso. Jpn. J. Ophthalmol. 2006, 50, 483-484. [CrossRef] [PubMed]

34. Czepita, D.; Mojsa, A.; Ustianowska, M.; Czepita, M.; Lachowicz, E. Prevalence of refractive errors in schoolchildren ranging from 6 to 18 years of age. Ann. Acad. Med. Stetin. 2007, 53, 53-56.

35. O'Donoghue, L.; McClelland, J.F.; Logan, N.S.; Rudnicka, A.; Owen, C.; Saunders, K. Refractive error and visual impairment in school children in Northern Ireland. Br. J. Ophthalmol. 2010, 94, 1155-1159. [CrossRef]

36. Read, S.A.; Collins, M.; Vincent, S. Light Exposure and Eye Growth in Childhood. Investig. Opthalmol. Vis. Sci. 2015, 56, 6779-6787. [CrossRef] [PubMed]

37. Gomes, A.C.G.; Castro, L.R.; de Brito, L.M.P.; da Cunha, M.A.; Ribeiro, M.V.M.R.; Gomes, A.C.G. Myopia caused by the use of electronic devices screen: A literature review. Rev. Bras. Oftalmol. 2020, 79, 350-352. [CrossRef]

38. Balarabe, A.H.; Adamu, I.; Abubakar, A. Vision screening to detect refractive errors in three selected secondary schools in Birnin Kebbi, North West, Nigeria. Sahel Med. J. 2015, 18, 61. [CrossRef]

39. Sewunet, S.A.; Aredo, K.K.; Gedefew, M. Uncorrected refractive error and associated factors among primary school children in Debre Markos District, Northwest Ethiopia. BMC Ophthalmol. 2014, 14, 95. [CrossRef]

40. Halim, A.; Suganda, R.; Sirait, S.N.; Memed, F.K.; Syumarti; Rini, M.; Ratnaningsih, N. Prevalence and associated factors of uncorrected refractive errors among school children in suburban areas in Bandung, Indonesia. Cogent Med. 2020, 7, 1737354. [CrossRef]

41. Yang, Z.; Jin, G.; Li, Z.; Liao, Y.; Gao, X.; Zhang, Y. Global Disease Burden of Uncorrected Refractive Error among Adolescents from 1990 to 2019; Research Square: Durham, NC, USA, 2021; pp. 1-17.

42. Sachan, N.; Srivastava, D.; Jain, P.K.; Bajpai, P.K.; Singh, S.K.; Mehra, J. Prevalence of undetected refractive errors among school children: A cross sectional study in urban Etawah, India. Int. J. Community Med. Public Health 2018, 5, 4608-4612. [CrossRef]

43. Kandel, H.; Khadka, J.; Goggin, M.; Pesudovs, K. Impact of refractive error on quality of life: A qualitative study. Clin. Exp. Ophthalmol. 2017, 45, 677-688. [CrossRef] [PubMed]

44. American Optometric Association. Evidence-Based Clinical Practice Guideline: Comprehensive Pediatric Eye and Vision Examination. Optom. Clin. Pr. 2020, 2, 2-67. [CrossRef]

45. Funarunart, P.; Tengtrisorn, S.; Sangsupawanich, P.; Siangyai, P. Accuracy of noncycloplegic refraction in primary school children in southern Thailand. J. Med. Assoc. Thail. 2009, 92, 806-812.

46. Mukash, S.N.; Kayembe, D.L.; Mwanza, J.-C. Agreement between Retinoscopy, Autorefractometry and Subjective Refraction for Determining Refractive Errors in Congolese Children. Clin. Optom. 2021, 13, 129-136. [CrossRef]

47. Park, S.H. Current Management of Childhood Amblyopia. Korean J. Ophthalmol. 2019, 33, 557-568. [CrossRef] 